\title{
CHIASMA FREQUENCY VARIATION WITH ALTITUDE IN CEPAEA HORTENSIS (MÜLL.)
}

\author{
DAVID J. PRICE \\ Department of Biology and Geology, The Polytechnic of North London, Holloway Road, \\ London N7 8DB
}

Received: $29 . i .75$

\section{SUMmary}

Populations of Cepaea hortensis have been sampled from an area of $121 \mathrm{sq} \mathrm{km}$ on the north slopes of the Brendon Hills, Somerset, and analysed for chiasma frequency. Variation in chiasma frequency is due to variation in a single large bivalent-the A group bivalent. In 12 populations studied during 1973 no association between chiasma frequency and ecological factors could be detected. In particular, there is no evidence of a negative correlation of population density with chiasma frequency which is known to exist in populations of $C$. nemoralis within the area. In 1974, 17 populations, four of which were utilised in the 1973 analysis, were studied. Negative correlations of interstitial (but not total or terminal) chiasma frequency and between-cell variance with altitude were found. It is likely that the correlation of betweencell variance with altitude is due to the strong correlation of variance with chiasma frequency which exists in these populations. There is evidence from several populations that chiasma frequency is stable between years. The implications of the negative correlation of chiasma frequency with altitude and the lack of a correlation with population density are discussed.

\section{INTRODUCTION}

LAND snails of the genus Cepaea (Held.), and in particular C. nemoralis (L.) and $C$. hortensis (Müll.), have been the subject of many ecogenetic studies because of a striking genetic polymorphism for shell colour and banding (summaries by Ford, 1971; Williamson, 1972). Linkage relationships between the relevant loci are similar in $C$. nemoralis and $C$. hortensis but there is indirect evidence that they respond differently to similar selective pressures. For example, on the north slopes of the Brendon Hills, Somerset, $C$. nemoralis becomes less abundant on an east-west axis and the degree of polymorphism declines as the species approaches the edge of its range in the area so that several colonies in the east are monomorphic (Bantock and Price, 1975a). In contrast, in $C$. hortensis in this area the main geographical patterns involve linkage states which vary with altitude (Bantock and Noble, 1973). Climatic factors have been implicated in the distribution and variation of both species.

Whereas the visual polymorphism has been studied throughout the species' ranges, information on the population cytogenetics is limited entirely to populations situated in Somerset, S.W. Britain, and thus concern only a very limited part of the ranges of the two snails. Variations in chiasma frequency is virtually restricted to variation on a single large bivalent in both species (Price, 1974; Price, in press). Bantock (1972) described a population of $C$. nemoralis on Exmoor where chiasmata were low in frequency and localised in position whereas studies to the north of the Brendon Hills show that chiasma frequencies are higher and vary between populations in 
both species (Price, 1974; Price, in press). Comparisons between the species in sympatric populations in this area showed that $C$. hortensis is less variable in chiasma frequency and it was suggested that this may be due to a differential response to the same selective agencies (Price, in press).

Price and Bantock (1975) have shown also that in $C$. nemoralis in this area there is a negative correlation between population chiasma frequency and density, irrespective of other factors such as the degree of visual polymorphism and geographical position. The purpose of this paper is to determine either whether the same relationship occurs in $C$. hortensis or, if not, whether chiasma frequency is associated with other identifiable factors.

TABLE 1

Population locations and summary of cytogenetic data from the A group bivalent (based on 30 cells per snail)

Sample Means

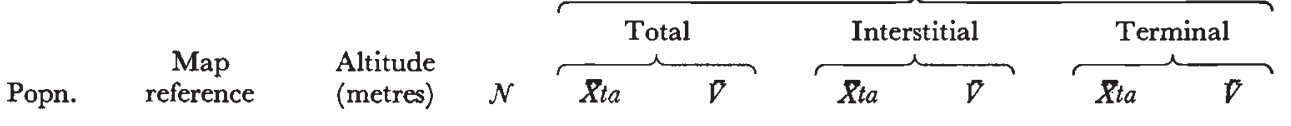

$\begin{array}{rr}1 * & \text { ST03.054374 } \\ 2 * & \text { ST03.055398 } \\ 3 * & \text { ST04.010435 } \\ 4 * & \text { ST04.017421 } \\ 5 * & \text { ST03.052375 } \\ 6 * & \text { ST03.041393 } \\ 7 * & \text { ST03.037376 } \\ 8 * & \text { ST04.037416 } \\ 9 * & \text { ST04.018425 } \\ 10^{*} & \text { ST03.066395 } \\ 11 * & \text { ST03.068387 } \\ 12 * & \text { ST04.031423 }\end{array}$

108
99
16
45

18
16
13
18
15
17
17
18
12
17
18
8

A. Samples collected and analysed in 1973

$\begin{array}{llllll}1.856 & 0.148 & 1.539 & 0.132 & 0.317 & 0.092 \\ 1.819 & 0.141 & 1.525 & 0.124 & 0.294 & 0.081 \\ 1.923 & 0.169 & 1.603 & 0.144 & 0.321 & 0.086 \\ 2.054 & 0.138 & 1.691 & 0.138 & 0.363 & 0.093 \\ 1.818 & 0.146 & 1.529 & 0.115 & 0.289 & 0.092 \\ 1.720 & 0.130 & 1.475 & 0.116 & 0.245 & 0.074 \\ 1.963 & 0.130 & 1.616 & 0.124 & 0.347 & 0.099 \\ 1.891 & 0.141 & 1.654 & 0.136 & 0.237 & 0.073 \\ 1.756 & 0.130 & 1.536 & 0.133 & 0.219 & 0.069 \\ 1.820 & 0.115 & 1.582 & 0.120 & 0.237 & 0.072 \\ 1.700 & 0.135 & 1.511 & 0.122 & 0.189 & 0.060 \\ 1.929 & 0.110 & 1.638 & 0.114 & 0.292 & 0.088\end{array}$

B. Samples collected in 1973, analysed in 1974

$\begin{array}{rr}4 & \text { ST04.017421 } \\ 10 & \text { ST03.066395 }\end{array}$

$\begin{array}{ll}45 & 13 \\ 69 & 14\end{array}$

$\begin{array}{llllll}2.064 & 0.150 & 1.718 & 0.156 & 0.346 & 0.095 \\ 1.864 & 0.122 & 1.617 & 0.125 & 0.247 & 0.075\end{array}$

C. Samples collected and analysed in 1974

\begin{tabular}{|c|c|c|c|c|c|c|c|c|c|}
\hline $1 *$ & ST03.054374 & 108 & 14 & $1 \cdot 862$ & $0 \cdot 145$ & 1.526 & 0.128 & 0.336 & 0.095 \\
\hline $2 *$ & ST03.055398 & 99 & 11 & $1 \cdot 836$ & $0 \cdot 140$ & $1 \cdot 551$ & 0.125 & 0.285 & 0.083 \\
\hline $5^{*}$ & ST03.052375 & 150 & 14 & $1 \cdot 783$ & $0 \cdot 141$ & $1 \cdot 512$ & 0.125 & 0.271 & 0.089 \\
\hline $10^{*}$ & ST03.066395 & 69 & 13 & $1 \cdot 823$ & $0 \cdot 121$ & 1.577 & $0 \cdot 123$ & $0 \cdot 246$ & 0.075 \\
\hline 13 & ST03.057377 & 93 & 15 & $1 \cdot 802$ & $0 \cdot 152$ & 1.515 & 0.141 & $0 \cdot 287$ & 0.090 \\
\hline 14 & ST03.066400 & 45 & 13 & 1.972 & $0 \cdot 160$ & 1.577 & $0 \cdot 140$ & 0.395 & $0 \cdot 101$ \\
\hline 15 & ST03.048365 & 189 & 14 & $1 \cdot 740$ & $0 \cdot 128$ & $1 \cdot 440$ & 0.105 & $0 \cdot 300$ & 0.085 \\
\hline 16 & ST03.057362 & 282 & 13 & $1 \cdot 792$ & $0 \cdot 158$ & $1 \cdot 464$ & $0 \cdot 132$ & $0 \cdot 328$ & 0.089 \\
\hline 17 & ST03.044351 & 330 & 12 & $1 \cdot 783$ & $0 \cdot 153$ & 1.497 & 0.117 & 0.286 & 0.082 \\
\hline 18 & ST04.059409 & 40 & 12 & $2 \cdot 155$ & $0 \cdot 197$ & $1 \cdot 797$ & $0 \cdot 195$ & $0 \cdot 358$ & 0.095 \\
\hline 19 & ST04.060411 & 37 & 11 & $2 \cdot 073$ & $0 \cdot 163$ & $1 \cdot 727$ & $0 \cdot 171$ & $0 \cdot 346$ & 0.094 \\
\hline 20 & ST04.061413 & 35 & 11 & $2 \cdot 170$ & $0 \cdot 169$ & $1 \cdot 843$ & $0 \cdot 184$ & 0.327 & 0.090 \\
\hline 21 & ST04.061415 & 34 & 12 & $2 \cdot 253$ & $0 \cdot 176$ & $1 \cdot 908$ & $0 \cdot 176$ & 0.345 & 0.090 \\
\hline 22 & ST03.050357 & 318 & 13 & $1 \cdot 913$ & $0 \cdot 165$ & $1 \cdot 556$ & $0 \cdot 144$ & 0.357 & 0.098 \\
\hline 23 & ST03.047343 & 347 & 15 & 1.895 & $0 \cdot 159$ & $1 \cdot 484$ & $0 \cdot 130$ & 0.411 & $0 \cdot 118$ \\
\hline 24 & ST03.044344 & 352 & 13 & 1.941 & $0 \cdot 177$ & $1 \cdot 600$ & $0 \cdot 142$ & $0 \cdot 341$ & $0 \cdot 101$ \\
\hline 25 & ST03.039345 & 357 & 12 & 1.953 & $0 \cdot 156$ & $1 \cdot 497$ & $0 \cdot 135$ & 0.456 & 0.112 \\
\hline
\end{tabular}

$\mathcal{N}=$ number of snails in sample, $\boldsymbol{X} t a=$ mean number of chiasmata, $\bar{\nabla}=$ mean transformed betweencell variance. *Data taken from Price (1975). 


\section{MAterials AND MEthods}

All the populations utilised in this study were sampled from an area of $121 \mathrm{sq} \mathrm{km}$ on the north slopes of the Brendon Hills, Somerset. The area is described more fully elsewhere (Bantock and Price, 1975a). Locations of the population sites are given in table 1 . The first part of this investigation was concerned with assessing the relationship between population density and chiasma frequency. Release-recapture methods were used to provide size estimates for 12 populations by sampling on three occasions during 1973. The sampling procedure was the same as that previously described for C. nemoralis (Price and Bantock, 1975). Estimates were calculated by using where possible (1) the Jolly method (Jolly, 1965), (2) the modified Lincoln Index (Lincoln, 1930; Parr et al., 1968) and (3) the total number of individual snails found on three occasions excluding recaptures $(=\mathrm{N} 3)$. Only adult snails were used.

The results obtained from the above investigation indicated the desirability of examining further an apparent relationship between altitude and chiasma frequency. During 1974, 17 populations were therefore sampled from a single valley system - the Nettlecombe valley (see Bantock and Noble, 1973). The altitude of these population sites varies between 34 and 357 metres.

The usual methods of preparation and of scoring chiasmata were followed. Heat-dried slides of the ovotestis were prepared (Bantock and Price, 1975b) and 30 diplotene spermatocytes were scored for chiasmata from each snail. C. hortensis has 21 small bivalents and one large bivalent termed the A group bivalent (Price, in press). Most of the small bivalents have a single chiasma. For example, in population 8 , only 23 out of a total of 11,340 bivalents had two chiasmata, this being the highest frequency recorded in any population of $C$. hortensis. In this paper, therefore, only the results for the A group bivalent will be given. There is some evidence (Price, in press) that on this bivalent terminal and interstitial chiasmata are independent of each other. Terminal and interstitial chiasmata were therefore recorded separately from each other and mean chiasma frequencies and between-cell variances were calculated for each snail. Between-cell variances were transformed for analysis using the following transformation- $\log _{10}\left(S^{2}+1 \cdot 0\right)$, where $S^{2}=$ between-cell variance.

\section{Results}

\section{(i) Chiasma frequency and population density}

Chiasma frequencies and density estimates are given for each of the 12 populations in tables 1 and 2. Estimates based on the Jolly method vary between 2.66 and 22.01 snails/sq $\mathrm{m}$. With the Lincoln Index estimates vary between 0.43 and 20.41 snails $/ \mathrm{sq} \mathrm{m}$. Four populations were not marked and these have estimated densities (by N3) below 1.95 snails/sq $\mathrm{m}$. Population densities were normalised for analysis and table 3 shows that there is no evidence for a negative correlation between chiasma frequency and population density. In fact, the majority of correlations are positive although none is significant. In view of the altitudinal changes in the ecogenetics of $C$. hortensis within the area (Bantock and Noble, 1973), partial 
correlation coefficients were calculated to take altitude into account and also the relative distance east of the populations since gene frequency changes also occur on an east-west axis (Bantock, personal communication). None of these partial correlations is significant (table 4) although there is a slight sign of a negative association of altitude with chiasma frequency.

TABLE 2

Population density estimates

Density per square metre estimated by:

$\begin{array}{cccc} & \text { N3 } & \begin{array}{c}\text { Modified } \\ \text { Lincoln Index }\end{array} & \begin{array}{c}\text { Jolly } \\ \text { method }\end{array} \\ 1 & 5.88 & 10.03 & 13.56 \\ 2 & 1.14 & - & - \\ 3 & 0.51 & - & - \\ 4 & 15.97 & 20.41 & 21.31 \\ 5 & 6.12 & 14.19 & 7.44 \\ 6 & 1.13 & - & - \\ 7 & 5.63 & 9.76 & 15 \cdot 74 \\ 8 & 1.95 & - & - \\ 9 & 3.67 & 5.45 & 2.66 \\ 10 & 5.53 & 11 \cdot 17 & 22 \cdot 01 \\ 11 & 3.51 & 5.86 & 7.95 \\ 12 & 0.41 & 0.43 & -\end{array}$

TABLE 3

Correlation coefficients $(r)$ between population densities and mean chiasma frequencies and between-cell variances of the $A$ group bivalent

\begin{tabular}{cccc} 
& \multicolumn{3}{c}{ Density estimated by: } \\
\cline { 2 - 4 } Degrees of freedom & 10 & Lincoln Index & Jolly method \\
Total & 0.262 & 0.156 & 5 \\
Chiasmata--Interstitial & 0.202 & -0.014 & 0.658 \\
Terminal & 0.253 & 0.299 & 0.659 \\
Total & -0.040 & 0.648 & 0.568 \\
Variances- Interstitial & 0.126 & 0.477 & 0.188 \\
Terminal & 0.250 & 0.203 & 0.024 \\
& No significant correlations $(P>0.05)$
\end{tabular}

TABLE 4

Partial correlation coefficient; between mean chiasma frequencies and between-cell variances of the $A$ group bivalent and other variables

$\begin{array}{lrrr}r \text { AC.BDE } & 0.464 & r \text { BC.ADE } & 0.457 \\ r \text { AD.BCE } & -0.238 & r \text { BD.ACE } & -0.461 \\ r \text { AE.BCD } & -0.466 & r \text { BE.ACD } & -0.281\end{array}$

No significant correlations $(P>0.05,7$ d.f.)

$A=$ mean interstitial chiasma frequency, $B=$ mean interstitial between-cell variance, $\mathrm{C}=$ density (estimated by $\mathrm{N} 3$ ), $\mathrm{D}=$ distance east, $\mathrm{E}=$ altitude. 
Thus, in these 12 populations, which were chosen from throughout the study area, there are no significant correlations between population chiasma frequency or between-cell variance and population density or geographical position.

(ii) Chiasma frequency and altitude in the Nettlecombe valley

The chiasma frequency data for these populations is shown in table 1 . Populations 18 to 21 all have higher chiasma frequencies than have previously been recorded for $C$. hortensis (they are however not as high as in some populations of $C$. nemoralis). There is a significant negative correlation between interstitial chiasma frequency and altitude (table 5, fig. 1) and

TABLE 5

Correlation coefficients $(r$ ) between altitude and mean chiasma frequencies and between-cell variances of the A group bivalent for populations in the Nettlecombe Valley

$\begin{array}{crc} & & P(15 \text { d.f. }) \\ \text { Total } & -0.438 & >0.05 \\ \text { Chiasmata-Interstitial } & -0.606 & 0.01 \\ \text { Terminal } & 0.325 & >0.05 \\ \text { Total } & -0.010 & >0.05 \\ \text { Variances- Interstitial } & -0.486 & 0.05-0.02 \\ \text { Terminal } & 0.448 & >0.05\end{array}$

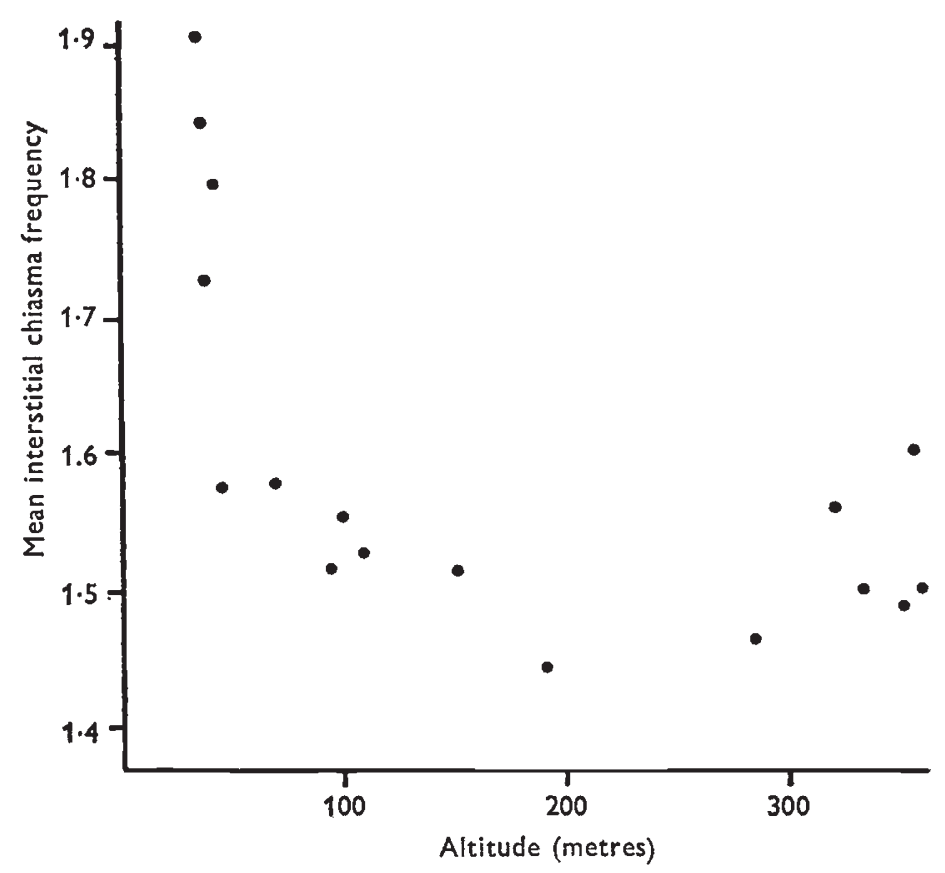

Fig. 1.-Association between altitude and mean interstitial chiasma frequency of the A group bivalent in populations of Cepaea hortensis from the Nettlecombe valley. 
also between interstitial between-cell variance and altitude (table 5, fig. 2). Correlations between altitude and total or terminal chiasma frequencies and variances, however, are not significant. There is a strong partial correlation (table 6) between interstitial chiasma frequency and betweencell variance, but the partial correlation between chiasma frequency and

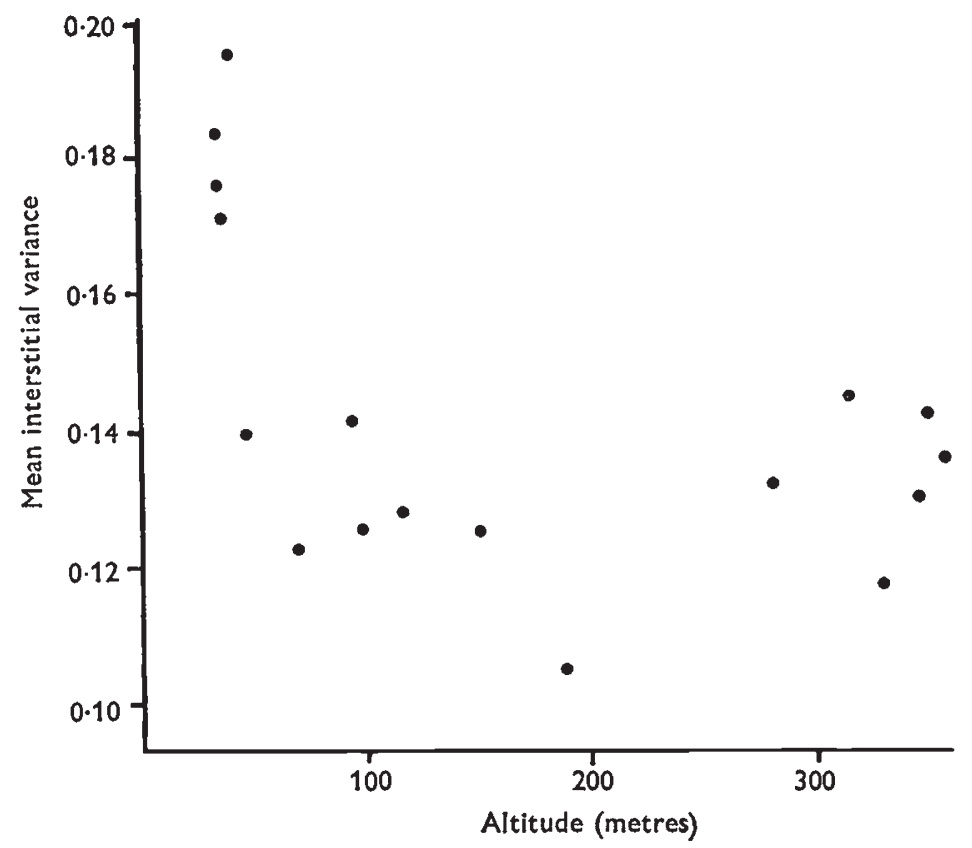

Fig. 2.-Association between altitude and mean transformed between-cell variance of interstitial chiasmata on the A group bivalent in populations of Cepaea hortensis from the Nettlecombe valley.

TABLE 6

Partial correlation coefficients between mean interstitial chiasma frequency $(A)$, mean interstitial betweencell variance $(B)$, and altitude $(C)$ for populations in the Nettlecombe Valley

$\begin{array}{lrc} & & \mathrm{P}(14 \text { d.f. }) \\ \text { rAB.C } & 0.878 & <0.001 \\ \text { rAC.B } & -0.447 & 0.10-0.05 \\ r \text { BC.A } & 0.184 & >0.05\end{array}$

altitude becomes just not significant $(P<0 \cdot 1)$ when between-cell variance is held constant. When chiasma frequency is held constant the correlation between variance and altitude changes sign and is not significant. This suggests that the correlation with altitude is largely due to chiasma frequency.

(iii) Stability of chiasma frequency

Four of the populations which were first sampled in 1973 were resampled in 1974 as part of the Nettlecombe valley study and thus provide an indication of the stability of chiasma frequency between years. Comparisons showed that there had been no significant changes $(P>0.05)$ 
between years in chiasma frequencies or between-cell variances in any of these populations.

Snails from two populations with different chiasma frequencies $(\mathrm{P}<0.05)$ which were sampled in 1973 were kept under similar laboratory conditions for a year and then prepared in 1974. Differences between the populations were maintained and neither population differed significantly in chiasma frequencies or between-cell variances from the samples prepared in 1973.

\section{Discussion}

The results show that (1) there is no negative correlation of population density with chiasma frequency in $C$. hortensis and (2) there is a negative correlation of population chiasma frequency and altitude in the Nettlecombe valley.

The correlation between density and chiasma frequency in $C$. nemoralis was based on observations from 32 populations (Price and Bantock, 1975). However, the correlation is still significant $(P<0.05)$ when only the 12 populations which were also sampled for $C$. hortensis are considered. Also, the range of estimated population densities in $C$. nemoralis is similar to the range in $C$. hortensis. There is thus a clear difference between the species in the relationship between population density and chiasma frequency.

The results obtained with $C$. hortensis affect the interpretation of the situation in $C$. nemoralis. The breeding system is similar in the two species and the results therefore seem to rule out the possibility that the correlation in $C$. nemoralis is merely a second-order effect due to greater homology of chromosomes in smaller, more inbred populations. It was suggested (Price and Bantock, 1975) that high chiasma frequencies in small populations of C. nemoralis may compensate for a lack of release of variability due to an increased level of inbreeding. If this is so, then it may mean that there are other factors operating in $C$. hortensis to promote stability in this area which override the need to compensate for inbreeding effects. It was noted previously (Price, in press) that $C$. hortensis is less variable in chiasma frequency than $C$. nemoralis in this area although the mean chiasma frequency in the two species is similar.

The correlation of chiasma frequency with altitude in $C$. hortensis became apparent only when a single valley system was studied suggesting that the relationship may be a local one, but also indicating that conclusions relating to this aspect of chromosome behaviour may be incomplete without an ecological consideration of the populations. There is some indirect evidence that interstitial and terminal chiasmata are under different controls and it has been suggested that interstitial chiasmata are more important in producing effective recombination, this effect being enhanced by a positive correlation between chiasma frequency and between-cell variance (Price, in press). It is interesting, therefore, that the correlation with altitude is only significant for interstitial (but not for total or terminal) chiasma frequency and betweencell variance. Furthermore, in the 12 populations examined in 1973 where there was no correlation between chiasma frequency and other factors, the correlation between chiasma frequency and between-cell variance is also not significant $(r=0.444, \mathrm{P}>0.05)$, whereas in the 17 populations from the Nettlecombe valley this correlation is very strong $(r=0.905, \mathrm{P}<0.001)$. Partial correlation coefficients suggest that the correlation of between-cell 
variance with altitude is largely due to this correlation with chiasma frequency. No information on the heritability of chiasma frequency and between-cell variance is as yet available for Cepaea; it is possible that they are under a separate genetic control as deduced by Lawrence (1963) in Melandrium. Even if they are not, the biological effect of this correlation between chiasma frequency and between-cell variance will be the same. That is, populations with a high chiasma frequency and high variance will produce a greater gametic array than will populations with a high chiasma frequency but a low variance.

In Myrmeleotettix maculatus the frequency of B chromosomes in a population is positively correlated with its chiasma frequency and, within populations, individuals with $\mathrm{B}$ chromosomes tend to have higher chiasma frequencies than those without (Hewitt and John, 1967). The level of B chromosomes is negatively correlated with altitude, and Hewitt and John (1967) suggest that there is production of new and experimental genotypes under the optimal environmental conditions which exist at low altitudes. There is no evidence that low altitudes are more favourable than high altitudes in $C$. hortensis. However, data from meteorological stations within the area (Ratsey, 1973; and see Bantock and Noble, 1973) shows that climatic variation is greater at lower altitudes. There is a greater mean diurnal range at a site situated at $95 \mathrm{~m}$ compared with a site at $290 \mathrm{~m}$. Daily maxima are higher at the lower site but the average monthly minima for the lower site are sometimes low enough to offset its higher average maxima so that the upper site may have a higher mean monthly temperature. It may be that high chiasma frequency and variance in low-altitude populations is in response to this more variable climate. The results from the populations kept under laboratory conditions make it seem unlikely that environment effects chiasma frequency directly-selective effects appear more probable. It ought to be possible to transplant populations from high to low altitudes and vice versa: the response of these populations, as measured by chiasma frequency, to a changed environment could then be assessed.

A measure of linkage disequilibrium $\left(D^{\prime}\right)$ described by Turner (1968) varies with altitude in the Nettlecombe valley (Bantock and Noble, 1973). The direction of the variation suggests that a greater variety of chromosomal types within the colour and banding supergene exist at low altitudes. It is interesting that the present study shows that within the same area chiasma frequency variation is also greater at low altitudes. However, in Lolium and Festuca, populations with high chiasma frequencies exhibit less phenotypic variability of characters under polygenic control (Rees and Dale, 1974). In view of these results it is obvious that other gene loci, in both polygenic and major gene systems, must be considered before any definitive statement can be made about chiasma frequency and the genetic variability of populations of $C$. hortensis.

In relation to the visual polymorphism, until data from breeding programmes currently being undertaken by $\mathrm{G}$. $\mathrm{R}$. Bantock become available, it is not possible to conclude that there is a relationship between recombination within the supergene and the occurrence of particular chiasmata on the A group bivalent. Finally, it would be worth while to compare the present results with those from another area where a similar relationship between altitude and the visual polymorphism exists, e.g. at Rickmansworth, Hertfordshire (Cameron, 1969). 
Acknowledgments. - I am grateful to Dr C. R. Bantock, Miss K. Noble of the Leonard Wills Field Centre, and to M. Ratsey for help in collecting the snails. I am also indebted to Dr C. R. Bantock for his suggestions and critical reading of the manuscript.

\section{REFERENCES}

BANTOCK, C. R. 1972. Localisation of chiasmata in Cepaea nemoralis L. Heredity, 29, 213-221. BANTOCK, C. R., AND NOBLE, K. 1973. Variation with altitude and habitat in Cepaea hortensis (Müll.). Zool. 7. Linn. Soc., 53, 237-252.

BANTOCK, C. R., AND PRICE, D. J. 1975a. Marginal populations of Cepaea nemoralis (L.) on the Brendon Hills, England. I. Ecology and ecogenetics. Evolution, 29, 267-277.

BANTOCK, C. R., AND PRICE, D. J. 1975b. The cytology of Cepaea nemoralis. In Laboratory Manual of Cell Biology (ed. D. O. Hall et al.). English Universities Press, London.

CAMERON, R. A. D. 1969. The distribution and variation of three species of land snail near Rickmansworth, Hertfordshire. Zool. F. Linn. Soc., 48, 83-111.

FORD, E. B. 1971. Ecological Genetics, 3rd ed. Chapman and Hall, London.

HEWITT, G. M., AND JOHN, B. 1967. The B-chromosome system of Myrmeleotettix maculatus (Thunb.). III. The statistics. Chromosoma, 21, 140-162.

JoLLY, G. M. 1965. Explicit estimates from capture-recapture data with both death and immigration: stochastic model. Biometrika, 52, 225-247.

LAWRENCE, C. W. 1963. Genetic studies on wild populations of Melandrium. 1. Chromosome behaviour. Heredity, 18, 135-147.

LINCOLN, F. C. 1930. Calculating waterfowl abundance on the basis of banding returns. U.S.D.A. Circu., 118, 1-4.

PARR, M. J., GASKELL, T. J., AND GEORGE, B. J. 1968. Capture-recapture methods of estimating animal numbers. F. Biol. Educ., 2, 95-117.

PRICE, D. J., 1974. Variation in chiasma frequency in Cepaea nemoralis. Heredity, 32, 211-217.

PRICE, D. J. 1975. Chiasma frequency variation in Cepaea hortensis (Müll.) and a comparison with $C$. nemoralis (L.). Genetica. (In press.)

PRICE, D. J., AND BANTOCK, C. R. 1975. Marginal populations of Cepaea nemoralis (L.) on the Brendon Hills, England. II. Variation in chiasma frequency. Evolution, 29, 278-286.

RATSEY, s. 1973. The climate at and around Nettlecombe Court, Somerset. Field Studies, 3, 741-757.

REES, H., AND DALE, P. J. 1974. Chiasmata and variability in Lolium and Festuca populations. Chromosoma, 47, 335-351.

TURNER, J. R. G. 1968. On supergenes. II. The estimation of gametic excess in natural populations. Genetica, 39, 82-93.

williamson, m. 1972. The Analysis of Biological Populations. Edward Arnold, London. 